\title{
CURSOS Y DISCURSOS ESCOLARES EN LAS TRAYECTORIAS JUVENILES
}

\author{
FELIPE GHIARDO SOTO* \\ OSCAR DÁVILA LEÓN**
}

\begin{abstract}
RESUMEN
Diferentes estudios sobre juventud han venido adoptando el enfoque de trayectorias como una entrada al fenómeno juvenil. La potencia de este enfoque es que permite ligar en un mismo ejercicio analítico las dimensiones estructurales, educacionales y laborales que influyen en el proceso de construcción social de juventudes. Su aplicación ha resultado de gran relevancia para entender las condiciones juveniles en países europeos. Sin embargo, en Chile han existido pocas iniciativas de investigación que intenten este tipo de aproximaciones. El presente artículo intenta aplicar el enfoque de trayectorias al análisis de un sector específico de la juventud: la que asiste a los establecimientos de educación pública municipal. El propósito es intentar describir la trayectoria de estos jóvenes abordando de manera integrada sus características estructurales o de origen, sus trayectos escolares y la exploración de los distintos modos en que proyectan su futuro en los planos educacional, laboral y familiar.

PALABRAS CLAVE: TRAYECTORIAS, CAPITALES, PROYECTOS DE VIDA, CONDICIÓN JUVENIL

* Investigador del Centro de Estudios Sociales CIDPA, Valparaíso, Chile. E-Mail: felipe@cidpa.cl.

** Investigador del Centro de Estudios Sociales CIDPA, Valparaíso, Chile. E-Mail: oscar@cidpa.cl.

El presente artículo se inscribe en el marco del proyecto de investigación «Trayectorias de vida y condiciones juveniles», el que ha contado con el apoyo de la Fundación Ford de Santiago de Chile.
\end{abstract}




\title{
CURSOS E DISCURSOS ESCOLARES NAS TRAJETÓRIAS JUVENIS
}

\begin{abstract}
RESUMO
Diferentes estudos sobre juventude têm adotado o enfoque de trajetórias como porta de entrada para o fenômeno juvenil. $\mathrm{O}$ alcance deste enfoque permite vincular num mesmo exercício analítico as dimensões estruturais, educacionais e de trabalho que influenciam o processo de construção social das juventudes. Sua aplicação tornou-se importante para a compreensão das condições juvenis em países europeus. No entanto, no Chile, poucas iniciativas de pesquisa têm empregado este tipo de abordagem. $\mathrm{O}$ presente artigo procura utilizar o enfoque de trajetórias na análise de um setor específico da juventude: aquele que freqüenta os estabelecimentos de educação pública municipal. O objetivo é tentar descrever a trajetória destes jovens, abordando de maneira integrada suas características estruturais ou de origem, seus percursos escolares e a exploração das diferentes maneiras pelas quais planejam seu futuro no campo educacional, de trabalho e familiar.
\end{abstract}

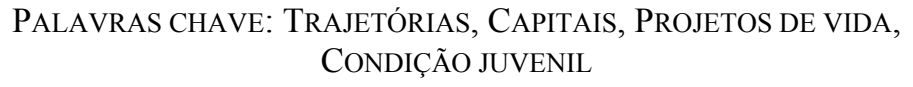

\section{SCHOOL COURSES AND SPEECHES IN THE TRAYECTORIES OF THE YOUNG}

\begin{abstract}
Different studies referred to the young, have been adopting the insight of trayectories as an entry point to the phenomenon of the young. The strength of this insight is that it allows to join in a same analysis process, the structural, educational and working extents that act on the social construction process of the young. The application of this insight has been of great importance in order to understand the conditions of the young in European countries. Nevertheless, in Chile there have been few research initiatives intending this kind of approach. The present article tries to apply the trayectories insight to the analysis of a specific sector of the young: that which assist to the educational institutions belonging to municipal public education. The purpose is to try to describe the trayectory of these young people facing in a integrated manner, their structural or origin features, their school stretches and exploration of the different ways with which they project their futures on the educational, laboral and family grounds.
\end{abstract}

KEY WORDS: TRAYECTORIES, CAPITALS, LIFE PROYECTS, JUVENILE CONDITIONS 


\section{INTRODUCCIÓN}

EN LAS SOCIEDADES CONTEMPORÁNEAS, el «factor escolar» se ha convertido en uno de los más potentes mecanismos de estructuración social. La ocupación que se tenga, el nivel de ingresos o el estilo de vida que se lleve dependen, en buena medida, del nivel de escolaridad; de ahí que mucho de lo que ocurra con el futuro de los sujetos dependa de su paso por el sistema escolar.

Quizás por eso, desde la década de los noventa hasta la fecha la educación y el sistema escolar han sido objetos de discusión y diagnóstico. Se formaron comisiones de expertos, se organizaron foros internacionales y se financió gran cantidad de estudios que en conjunto lograron bosquejar una imagen bastante completa sobre el estado de situación en el campo educativo. Con este conjunto de iniciativas se confirmaron dos temas que eran evidentes: la desigualdad educacional entre las clases, y la inequidad del sistema escolar, dos tendencias que quedan representadas en la figura de la educación pública municipalizada. ${ }^{1}$ Cada informe de resultados de las pruebas SIMCE y PSU, ${ }^{2}$ se ha encargado de confirmar su rezago respecto a los otros subsistemas, sobre todo al sistema privado de educación. Y cada nuevo informe con las estadísticas de ingreso al sistema universitario han obligado a reconocer que las diferencias que se producen en el período de educación formal se trasladan a la estructura social, que ha venido reservando sus posiciones más ventajosas a los grupos con más y mejores estudios.

Y sin embargo, o quizás por eso mismo, la presencia de la población joven de los estratos de más escasos recursos en el sistema escolar sigue creciendo y prolongándose (cf. Mideplan, 2003). Todo pareciera indicar que la promesa del discurso escolar no es objeto de ma-

1 La estructura del sistema escolar chileno diferencia tres tipos de establecimientos de acuerdo al carácter de su administración: uno de tipo público que depende directamente de los municipios, otro que es mantenido por un sostenedor privado que recibe subvención del Estado (que incluye los administrados por corporaciones) y un tercer tipo de establecimientos que depende exclusivamente de agentes privados.

2 SIMCE es la sigla de «Sistema de Medición de la Calidad de la Educación», prueba estandarizada que se aplica en todo Chile cada tres años a los cuartos y octavos años básicos, y a los segundos años medios. PSU es la sigla de «Prueba de Selección Universitaria», que se aplica todos los años. 
yor cuestionamiento. En efecto, la confianza que se deposita en la escolaridad como herramienta básica para «ocupar un lugar» en la sociedad viene creciendo. Así lo demuestran los antecedentes de la encuesta a los actores de la educación que cada dos años viene realizando el Centro de Investigación y Desarrollo de la Educación (CIDE, 2003). Pero también se ha demostrado que esa confianza se gradúa y vuelve relativa cuando se introducen variables «estructurales» como el estrato socieconómico y el tipo de sistema escolar al que se asiste (cf. PNUD, 1998). De ahí que resultara pertinente preguntarse sobre los jóvenes que asisten al sistema municipalizado, que representan, a fin de cuentas, el sujeto que encarna en cuerpo y mente todas estas desigualdades e inequidades. ${ }^{3}$ Cuáles son sus características, qué están pensando hacer con su futuro, hacia dónde están dirigiendo sus apuestas, cuáles son los factores que marcan la diferencia, fueron algunas de las preguntas que ocuparon el centro de un estudio que durante el año 2004 realizó el Centro de Estudios Sociales CIDPA de Valparaíso con el apoyo de la Fundación Ford.

El propósito del estudio fue intentar describir las principales tendencias en las trayectorias de los jóvenes que estudian en el sistema municipalizado, incluyendo distintas realidades sociales y educativas. Para eso se tomó como universo de población la que asiste a la educación secundaria del sistema municipalizado de tres comunas de la $\mathrm{V}$ Región de Valparaíso: Puchuncaví, Quillota y Viña del Mar, ${ }^{4}$ com-

3 La estructura administrativa del sistema escolar chileno presenta una marcada segmentación socioeconómica. De acuerdo a antecedentes del año 2000 , el $72,1 \%$ de la población que asiste a la educación media en establecimientos municipales pertenece a los cinco primeros deciles, que son lo de más bajos ingresos; la que asiste al sistema particular subvencionado pertenece principalmente a los deciles III al VIII; y la que asiste a los establecimientos particulares pagados proviene principalmente de los deciles VIII, IX y X, pero especialmente de este último (Mideplan, 2001).

4 Viña del Mar es una ciudad, si se quiere, «moderna», con una población numerosa que llegaba a 286.931 habitantes el año 2003, una economía que incluye múltiples áreas, en buena medida ligadas al turismo y el comercio, pero también a la industria. Quillota conforma una urbe intermedia, su población el año 2003 llegaba a 75.916 habitantes, con un porcentaje de población rural que llega al $13 \%$. Aunque la actividad económica está ligada principalmente a la agricultura, también incluye actividad industrial. Puchuncaví es, de las tres comunas seleccionadas, 
puesto en total por doce establecimientos. La metodología consistió en la aplicación de una encuesta - un cuestionario de autoaplicación-. La construcción de la muestra siguió un criterio de saturación, y la muestra efectiva llegó a los 6.496 casos, que corresponde al total de estudiantes que asistieron a clases el día que se aplicó el instrumento. Complementariamente, se efectuaron cinco grupos de discusión temáticos, que permitieron un mejor acercamiento a los componentes de los discursos que elaboran estos jóvenes al referirse a la educación, el futuro y la condición juvenil. Los principales resultados y algunos temas de discusión es lo que a continuación se presenta.

\section{LOS PUNTOS DE PARTIDA}

Para empezar, conviene aclarar nuestro objeto de estudio: las trayectorias. Digamos que el enfoque de trayectorias sociales asume varios supuestos básicos. El primero es que el curso de vida de un sujeto puede dibujarse como una trayectoria. El segundo, que el análisis de una trayectoria requiere establecer criterios y mecanismos que permitan asignar posiciones a los individuos en un espacio. El tercero, que las dimensiones de ese «espacio social», como lo llama Bourdieu (cf. Bourdieu, 1988), deben corresponder a los factores que más determinan la estructura que adquiere un sistema de distribución social de posiciones, o de «capitales», como dice el mismo Bourdieu. El cuarto, que la trayectoria será función de las variaciones en los niveles de esos capitales que registra un individuo o un grupo de individuos en un lapso de tiempo.

Aclarado lo anterior, queda asumir que para observar el curso de una trayectoria, en nuestro caso, la trayectoria de los jóvenes que

la de menor cantidad de habitantes. Su población el año 2003 llegaba a los 12.954 , con un $14 \%$ de población rural. Este municipio administra dos de las localidades que participaron en el estudio, Puchuncaví y Ventanas, distantes unos 7 kilómetros una de otra. En cada una funciona una unidad educacional dependiente del municipio. Puchuncaví tiene un pasado más ligado a la actividad agrícola; mientras el pasado de Ventanas estuvo ligado a principalmente a la pesca artesanal. Hoy en día, sin embargo, buena parte de la población económicamente activa de ambas localidades es absorbida por el polo industrial de Ventanas, principalmente por las refinerías de cobre de la Corporación del Cobre y la planta de la industria química Oxiquim, y por actividades ligadas al turismo que se desarrolla en balnearios que están en la zona. 
asisten al sistema de educación municipalizada, se nos impone como exigencia práctica fijar un punto que sirva de referencia para el análisis. Sólo fijando una posición de partida se puede describir el curso de una trayectoria. Para nuestros efectos, teniendo en cuenta el peso que tiene el «capital escolar» en la estructuración de las sociedades contemporáneas, asumiendo además que estamos concentrados en el campo de la educación, ese punto de partida tendrá como referencia el nivel de escolaridad de los padres.

\section{Cuadro 1}

Nivel de escolaridad de la madre y el padre

\begin{tabular}{|l|c|c|}
\hline Nivel de escolaridad & Madre & Padre \\
\hline Básica incompleta & 20,2 & 19,2 \\
\hline Básica completa & 19,1 & 17,2 \\
\hline Media incompleta & 20,2 & 17,5 \\
\hline Media completa & 25,8 & 27,3 \\
\hline Superior incompleta & 5,3 & 5,9 \\
\hline Superior completa & 9,4 & 12,9 \\
\hline
\end{tabular}

Sobre esto, hay dos cosas importantes que señalar. La primera es que, considerando el total de la muestra, se observa que los niveles de escolaridad que presentan los apoderados del sistema municipalizado de estas comunas son, en su mayoría, bajos. De todas las categorías, la más frecuente es que los padres y madres tengan educación secundaria completa. No obstante, si se suman las tres categorías inferiores, resulta que la mayoría de los padres $(54,9 \%)$ y de las madres $(59,5 \%)$ presenta niveles de escolaridad inferiores a la secundaria completa, en la actualidad el nivel mínimo exigido para acceder a la gran mayoría de los puestos formales de trabajo. Si a ello le agregamos que los niveles de ingreso promedio mensual de las familias que asisten a estos establecimientos fluctúan entre los $\$ 80.000$ (unos 150 dólares) y los $\$ 250.000$ (unos 450 dólares), nos podemos formar una imagen aproximada sobre la posición que ocupan las familias de los jóvenes que asisten al sistema municipalizado y sobre los niveles de «capital escolar» y económico que forman su herencia.

El segundo punto importante es que al interior del sistema municipalizado, también se produce una estructuración bastante importante. En efecto, si por un lado es cierto que al interior de cada estableci- 
miento conviven jóvenes con padres que tienen distintos niveles de escolaridad, entre los establecimientos se observan diferencias más o menos significativas en el peso de cada grupo en la composición de la matrícula. Existen liceos como el Liceo de Niñas de Viña del Mar en que es considerablemente más alta que en otros la proporción de madres y padres con estudios superiores, y otros como el Liceo Industrial de Viña del Mar o el Liceo Agrícola de Quillota, en que la mayor parte de los padres y madres presenta niveles de escolaridad iguales o inferiores a la secundaria incompleta. Lo interesante de este punto es que esta segmentación intra-sistema municipalizado, que en buena medida se asocia a los exámenes de admisión que algunos establecimientos aplican para filtrar el acceso, tienden a establecer distinciones entre los propios estudiantes que, como veremos más adelante, se vierten luego sobre sus posibilidades de trayectoria.

\section{EL TRAYECTO O LOS CAPITALES ACUMULADOS}

El análisis de las trayectorias parte estableciendo que para cada grupo de individuos que ocupa una posición similar en la estructura social, se impone un abanico de posibilidades relativamente definido y más o menos común. Este es el efecto de destino que impone la situación de clase, que define posibilidades de trayectorias diferentes para los miembros de clases diferentes, y similares para quienes comparten una misma condición. Pero así como asume esta suerte de «determinismo estructural», también asume que siempre queda un margen de posibilidad para que en cada grupo se produzcan fracciones que construyen trayectorias que se despegan del campo de posibilidades que determina su condición de clase, que se desclasan, como diría Bourdieu, principalmente producto de incrementos o decrementos en los niveles de capital que resultan del propio movimiento o la propia acción.

La posibilidad que abre este efecto de trayectoria individual, como lo llamaba el mismo Bourdieu, nos movió a incorporar al análisis aquellos campos por los que se mueven habitualmente los jóvenes y en los que pudieran estar generando incrementos en sus «niveles de capital». Asumiendo que sería poco probable encontrar incrementos relevantes de «capital económico» que respondan a ingresos generados por los propios sujetos, preferimos concentrarnos en el campo cultural. Para esto abordamos dos dimensiones: una extra y otra intra escolar. Con la primera intentamos describir las principales tendencias que muestra la relación que han venido manteniendo estos jóvenes con 
el campo de la cultura por vías alternativas a la de la escuela. Los indicadores básicos serán el nivel de consumo cultural y el grado de manejo de herramientas de modernización. Con la segunda, pretendemos describir las principales tendencias en la relación con el proceso de escolarización, que a fin de cuentas, es el que más determina sus posibilidades de trayectoria.

\section{Consumo cultural}

Usar un término como el «consumo cultural» para observar la relación de los sujetos con la cultura, es en sí mismo problemático. Esto por, al menos, dos razones. La primera, porque tiende a restringir el asunto a las acciones de intercambio en un mercado de bienes culturales y a dejar fuera toda una gama de prácticas que, en rigor, no entran en la lógica de este mercado, pero que igualmente sirven al «autocultivo». La segunda, porque la polisemia de la palabra «cultura» complejiza y deja siempre expuesto a críticas cualquier análisis que la incluya como dimensión. Por eso creemos conveniente dejar aclarado que en este caso usamos un concepto extendido de «consumo cultural» que incluye una serie de prácticas que «inyectan cultura»; y que el concepto de «cultura» lo restringimos al de "cultura dominante», bajo el supuesto que es el grado de integración a estos moldes lo que indica si se participa o no, y en qué grado, de los «universos simbólicos» dominantes.

A modo de contexto, señalemos que las encuestas sobre consumo cultural que viene realizando el Instituto Nacional de Estadísticas (INE) con el Consejo Nacional de la Cultura y las Artes, han identificado dos tendencias principales. La primera es que son los tramos jóvenes los que más participan de este campo; y la segunda, que existe una evidente distancia entre los niveles de consumo cultural de los diferentes estratos socioeconómicos (cf. INE, 2005). Esta última tendencia nos sirve para comprender nuestras observaciones acerca del modo en que se plantea la relación de estos jóvenes con el campo de la cultura.

Tomando como referencia los valores de un índice construido en tres categorías, podemos señalar que entre estos jóvenes los contactos «cotidianos» con la cultura son algo poco habitual. En efecto, sólo un $9,6 \%$ presenta un nivel alto de «consumo cultural». La tendencia más frecuente fue ubicarse en un nivel de consumo cultural intermedio, donde se concentró el 76,4\% de los casos. Ahora, si a ello sumamos el porcentaje que presentó bajo nivel de consumo cultural, resulta que 
una gran mayoría, superior al 90\%, presenta una relación insuficiente con este campo. ${ }^{5}$

Ni la lectura, ni el cine, ni el arte son referentes importantes para la construcción de sus mundos. Sólo el $26 \%$ lee más libros que los mínimos exigidos por el currículo escolar, que desde ya son pocos; el $20 \%$ dice haber asistido al cine en el último mes, y $26 \%$ desarrolla alguna práctica artística. No ocurre lo mismo con los medios de comunicación masivos, que sí constituyen un referente comparativamente bastante más presente. De hecho, el $81 \%$ ve diariamente algún programa de la televisión abierta, y el $61 \%$ lee todos los días alguna sección de la prensa escrita. De ahí lo relevante del dato, pues si bien no implica asumir que absorban los contenidos de la televisión o de la prensa sin ningún filtro de crítica, el hecho mismo que sea tan masiva su llegada, vuelve irremediablemente necesaria la discusión sobre los mass media y su papel en la producción de cultura.

El punto que nos interesa destacar es que si, por un lado, el desarrollo frecuente de prácticas de consumo cultural no es independiente del grupo de origen - que en este caso representamos con el nivel de escolaridad de los padres-, su influencia no es lo suficientemente fuerte como para hablar de una «condición condicionante». Al cruzar ambas variables, resulta que efectivamente en los grupos con padres de más alta escolaridad son mayores los porcentajes de casos que se ubican en la categoría de alto consumo cultural. Sin embargo, hay grupos o fracciones dentro de los grupos con padres de baja escolaridad que han mantenido una relación más estrecha con «la cultura» que el resto de su mismo grupo e incluso que parte importante de quienes pertenecen a los grupos con padres de mayor escolaridad. También ocurre lo contrario, fracciones de los grupos que provienen de familias con mayores niveles de capital cultural que se ubican en niveles de consumo cultural iguales o más bajos que la moda. La presencia de estos grupos que han dibujado trayectos «ascendentes» $\mathrm{y}$ «descenden-

5 Un dato importante es que resultó levemente superior la proporción de hombres que de mujeres con bajo consumo cultural, y levemente mayor la proporción de mujeres que de hombres con alto consumo cultural, notorio sobre todo en la lectura. Estas tendencias, aunque sean estadísticamente poco significativas, son culturalmente relevantes, pues representan transformaciones complejas en la conformación de la identidad femenina en las generaciones más jóvenes de los estratos de menores recursos, donde tradicionalmente la mujer ha jugado un rol más pasivo en términos de inserción a la sociedad y la cultura. 
tes», dan pie para pensar que más que una condición estructural inquebrantable, la adquisición de cultura más bien refleja y a la vez configura una mentalidad, una disposición, un interés, que se asocia al tipo de cultura del grupo de pertenencia, pero que responde también a disposiciones individuales. De ahí el doble desafío para quienes dirigen las escuelas y liceos del sistema municipalizado, pues son precisamente estas instancias las que en potencia contienen la capacidad para despertar o incentivar el «gusto» por la cultura, y que tienen, al mismo tiempo, la facultad para generar espacios de acceso a la cultura que enriquezcan y potencien las expresiones de estos jóvenes. Hacerlo o no, ya es un problema de compromiso y de gestión.

\section{Herramientas de modernización}

Hablar de modernidad o modernización encierra un tema demasiado complejo como para pretender zanjarlo en este momento. Por eso preferimos limitarnos a partir de una constatación evidente: el lugar que ocupa el uso de las tecnologías en la construcción de las sociedades y culturas modernas. Las últimas revoluciones tecnológicas, sobre todo en el campo de la comunicación, han convertido al manejo de las tecnologías en herramienta casi obligada para integrarse a las transformaciones culturales que viene produciendo la «sociedad de las comunicaciones» o de la «información». La diferencia entre manejarlas o no es gravitante. Según plantea el informe sobre juventud que realizaran el Programa de las Naciones Unidas para el Desarrollo (PNUD) junto al Instituto Nacional de la Juventud (INJUV), para los jóvenes el manejo de las llamadas «herramientas de modernización» o de los lenguajes de la modernidad, resulta decisivo al momento de armar sus proyectos de vida y dotarlos de sentido (PNUD, 2003). Aquellos que participan de cerca de los procesos de modernización, los que están más «conectados», cuentan con más y mejores herramientas para imaginar su futuro. El punto está en que, como señala el mismo informe, si por un lado los más jóvenes corren con ventaja respecto a los grupos de mayor edad, entre los jóvenes existen diferencias marcadas que dependen del estrato socioeconómico al que se pertenezca (PNUD, 2003).

De algún modo esta última tendencia se confirma con los datos que pudimos producir, que describen una clara tendencia a mantener bajos niveles de contacto con las tecnologías y los lenguajes de la modernización. De acuerdo a los datos construidos por medio de un índice, resultó que del total de la muestra, sólo el 10\% presenta un alto 
grado de acceso de estas herramientas. La situación más frecuente - con un 56\% - fue tener un escaso acceso, y la segunda más frecuente - con un 17\% - fue tener nulo acceso. Lo complejo es que, si sumamos ambos porcentajes, resulta que el $73 \%$ de estos jóvenes presenta una precaria integración a procesos que a esta altura resultan básicos.

De todas las nuevas tecnologías, la que estos jóvenes más han incorporado a su mundo es la telefonía móvil: el 56,2\% dice tener celular propio, porcentaje alto si consideramos el costo de los equipos y los minutos de llamado. No obstante, en el resto de las tecnologías, la situación cambia. Una amplia mayoría $(65,8 \%)$ no posee un computador en su hogar. Pese a ello, el 47,3\% dice manejar al menos un programa computacional, en una diferencia que en el fondo releva el papel que viene jugando la institución escolar como instancia que «democratiza» el acceso a estas tecnologías. De todos modos, la imposibilidad de mantener un contacto permanente con un computador en el hogar, que según información de otras encuestas, es el lugar donde más se usa (cf. INJUV, 2004), es determinante en las diferencias de manejo del lenguaje computacional. De hecho, entre quienes tienen un computador en su hogar, el $68,1 \%$ maneja el lenguaje computacional, porcentaje que es considerablemente más alto que el $37,4 \%$ entre quienes no lo tienen.

El problema es que, a diferencia de lo que ocurre con el consumo cultural, en el manejo de herramientas de modernización las diferencias que produce el origen son más fuertes. Seguramente influye el hecho que el acceso a estas tecnologías se encuentre mediado por instrumentos y conexiones, y que ambas representen costos para las familias, difíciles de cubrir cuando se tienen bajos niveles de ingresos.

Ciertamente aquí también se observan fracciones de jóvenes que si bien pertenecen a los grupos con padres que presentan niveles bajos de escolaridad, se han venido incorporando de mejor manera a los procesos modernizadores que el patrón común de su grupo; pero son fracciones reducidas las que logran este efecto de trayectoria, y su presencia no alcanza a desviar la tendencia colectiva que apunta a mantener bajos niveles de integración a los procesos modernizadores. De hecho, para todos los grupos distribuidos según la escolaridad del padre o de la madre, el porcentaje más alto se ubica en una situación de escasa disponibilidad de herramientas de modernización. Todo pareciera indicar entonces que la desigualdad en este campo no está disuelta. A juzgar por los datos, la mayor parte de los jóvenes que 
asisten a estos establecimientos del sistema municipalizado todavía permanecen en la orilla perdida de la brecha digital. De ahí la importancia de programas gubernamentales que están tratando de abaratar los costos de los computadores y democratizar el acceso a internet; y de ahí también la necesidad de insistir en la responsabilidad que adquiere la institución escolar como ente reductor de estas desigualdades, que sólo podrá cumplir incorporando el uso de las tecnologías de la comunicación a las distintas materias - google-earth para la enseñanza de la geografía, por ejemplo-, y sobre todo, si no restringe el uso de los equipos y abandona el temor a hipotéticos destrozos por parte de sus propios estudiantes. ${ }^{6}$

\section{Trayectos escolares}

Las prácticas de consumo cultural y el contacto con las herramientas de modernización conforman mecanismos que efectivamente producen mayores grados de integración a la cultura y que pueden ser leídos como formas de «acumular» capital cultural. Sin embargo, estas prácticas, muchas veces autodidactas, no relevan en importancia a la institución escolar, que es la instancia con el más amplio radio difusor de cultura. Ella es, de hecho, la que más y de mejor manera puede producir incrementos masivos y sistemáticos en los niveles de capital cultural de las «clases bajas» o los «sectores populares», y reducir - o tratar de - su condición de desventaja. Por este motivo, intentar describir la variedad de formas que puede asumir el paso por el sistema escolar, entrega piezas que son importantes para armar la cadena que suponen las trayectorias. En lo que sigue, intentaremos tocar algunos puntos relativos a este tema.

a) El cursus escolar

Bourdieu utilizaba el concepto de cursus escolar para dar cuenta de la forma y el ritmo que adquiere el paso de cada individuo por el sistema escolar. El supuesto básico es que si éste tiene una determinada es-

6 Ésta fue una de las principales quejas que aparecieron en los grupos de discusión: la restricción que impone la dirección de los establecimientos al uso de los recursos, que según declaran los propios estudiantes, recurre a argumentos confusos para ocultar, en el fondo, la sospecha y el temor que sienten hacia sus propios estudiantes. 
tructura, y si el proceso de escolarización supone un «ritmo normal» (edades para el ingreso, edades para cada nivel, etc.), la forma que adquiera el paso por la escuela se convierte en un elemento decisivo para describir los trayectos seguidos y el curso que puedan tomar las trayectorias.

Sobre esto, el primer punto que intentamos explorar fue el momento en que se inicia la carrera escolar. No deja de sorprender que más del $60 \%$ de los jóvenes haya dicho haber recibido educación preescolar, pues el porcentaje considerablemente más alto que los niveles de cobertura actuales en este nivel de enseñanza. La magnitud de esta diferencia puede hacer poco confiable el dato, aunque existe la posibilidad de estancias intermitentes, con entradas y salidas.

El segundo punto fue registrar los movimientos que se pudieran haber producido respecto a los distintos subsistemas que componen la estructura administrativa del sistema escolar chileno. Para eso preguntamos por los tipos de establecimientos en los que habían estado. El resultado fue que el $65 \%$ de los jóvenes que hoy asiste a liceos del sistema municipalizado, siempre ha pertenecido a este sistema. El $35 \%$ restante ha pasado por uno o más de un sistema escolar. De ellos, $15 \%$ estudió en un establecimiento particular subvencionado, $2 \%$ en uno privado, y $18 \%$ alternó entre los distintos sistemas. El carácter «pagado» de los establecimientos privados hace que las variaciones en el tipo de establecimiento por el que se ha pasado mantenga un grado de relación importante con las condiciones de la familia. De hecho, en los grupos con padres de menor escolaridad, es bastante mayor la proporción de estudiantes que ha estudiado solamente en establecimientos municipales, mientras que los hijos de padres con mayor escolaridad, aumentan su participación en establecimientos particulares subvencionados y/o pagados. En este sentido, estos datos muestran que la mayor parte de los jóvenes pertenece a familias que no han variado o no han podido variar sus inversiones en educación, lo más probable, producto que han mantenido una misma condición socioeconómica; pero también demuestran que el sistema secundario municipalizado acoge a una porción importante de jóvenes que proviene de sectores de la población que en estos años han experimentado bajas y/o alzas y bajas en sus inversiones o en sus capacidades para invertir en la educación de sus hijos. Lo otro interesante es que, contrario a lo que se pudiera pensar, el haber pertenecido a sistemas de educación pagados no guarda mayor relación con el curso del proceso educativo. Haber pasado por establecimientos subvencionados o privados, que por lo ge- 
neral son los que obtienen los mejores resultados de rendimiento, no se traduce mecánicamente en ventajas comparativas importantes en términos de rendimiento. Por el contrario, éste es prácticamente independiente del tipo de establecimiento, lo que ciertamente obliga a graduar el discurso sobre la mejor calidad de la educación en el sistema privado, pero también a investigar más y de mejor manera qué ocurre con quienes migran desde estos sistemas al municipalizado.

Un tercer aspecto importante para describir el curso escolar de un sujeto es la correspondencia entre la edad y el nivel escolar. La lógica aquí es que si el curso de la escolarización define una edad para cada nivel, la correspondencia entre estos dos aspectos grafica la regularidad que ha seguido una trayectoria. Si analizamos la composición etaria de la muestra y la cruzamos luego con la variable curso, se observa que en cada nivel hay grados de dispersión bastante bajos, demostración de que el grueso de los alumnos muestra un curso escolar ajustado a la norma de su grupo. Las proporciones de casos que vienen con desfases notorios respecto al conjunto del grupo-curso son relativamente menores, aunque no deja de ser importante que ya en el primer año de la secundaria cerca del $20 \%$ se encuentre con uno o más años de retraso, y que incluso haya una proporción, pequeña por cierto, que recién se encuentra en este nivel con 20 años ya cumplidos. La repitencia es sin duda un factor fundamental para explicar estos desfases. Del total de casos que compone la muestra, hay un 19,7\% que repitió en la básica, 4\% de los cuales repitió más de una vez. Lo complejo es que hay una porción relativamente importante - $17,4 \%$ - de quienes repitieron en la básica que también repitieron en la media, incluso algunos más de una vez en uno o en ambos ciclos. El efecto es que su curso escolar se distancia del curso regular que suponen los ciclos escolares y termina por demorar su trayecto. Lo mismo produce la situación de maternidad y paternidad, que por lo general se traduce en el retraso de uno o dos años respecto al ciclo regular, si es que no termina en deserción o en el posterior ingreso a un establecimiento del tipo « 2 por $1{ }^{7}{ }^{7}$

7 La política educacional chilena contempla la alternativa de completar dos niveles en un solo año académico. El requisito es tener 18 años cumplidos. En los últimos años esta alternativa ha recibido un notorio impulso. Se han multiplicado las instituciones que imparten esta modalidad, sobre todo en el sector privado, se han creado programas de gran envergadura para promover la educación de adultos - ChileCalifica-, y la matrícula ha venido creciendo. 
El tercer punto en la descripción de este cursus escolar nos remite a la decisión por una modalidad de educación. Con esto nos situamos frente a uno de los hitos más importantes que reserva el paso por la educación secundaria, ${ }^{8}$ sobre todo para los jóvenes que asisten al sistema municipalizado, pues de ella depende en buena medida el devenir de su trayectoria. Si analizamos el comportamiento de esta población cuando se trata de tomar una opción formativa, lo primero que se observa es que la proporción de casos que opta por la Humanista Científica (HC) es mayor que el porcentaje que opta por la Técnico Profesional (TP). Los porcentajes respectivos son de un $53 \%$ en la modalidad HC y un $47 \%$ en la TP. De todos modos, la diferencia es bastante menor comparada con la de una década atrás. Sin ir más lejos, todavía en 1990 la modalidad HC tenía varios puntos de ventaja respecto a la TP. ${ }^{9}$ De ahí que la casi paridad entre ambas modalidades demuestra el impacto que ha tenido la política educativa de los últimos diez años, que ha promovido la formación técnica multiplicando su oferta y difundiendo con fuerza un discurso que busca legitimar esta alternativa formativa. El tema es que la ampliación de la oferta en la modalidad TP ha corrido en gran parte por cuenta del sistema municipalizado. El sistema de colegios particulares ha permanecido prácticamente ajeno a este proceso, pues salvo la creación de algunos establecimientos subvencionados con modalidad TP, en todo Chile existe sólo un establecimiento particular pagado que imparte formación en esta área. La opción por una modalidad no es, por tanto, un dilema que en la práctica se presente a quienes asisten al sistema particular de educación, sino que permanece reservada - principalmente - para quienes asisten a los establecimientos municipalizados. A esto seguramente se refería Bourdieu cuando decía que una de las funciones

8 En rigor, la opción por una modalidad se debiera tomar al momento de pasar al tercer nivel del ciclo secundario. Esa es la norma que establece la política educativa. En la práctica, sin embargo, los liceos industriales, comerciales y agrícolas, que cubren todos los niveles de la secundaria, adelantan esta decisión al momento de ingresar al primer año de la secundaria. De ahí que, para hacerlo comparativo, para esta parte del análisis vamos a considerar solamente a la población de tercero y cuarto año de enseñanza media.

9 El crecimiento en los niveles de matrícula en la modalidad Técnico Profesional es considerable: pasó de representar al 27,5\% de los estudiantes de enseñanza media en 1989, al 40\% el año 2003 (Mineduc, 2005). 
básicas de todo sistema escolar es «regular las expectativas» de los estudiantes (cf. Bourdieu y Passeron, 2003).

Lo que corresponde, entonces, es tratar de dar cuenta de los factores que pueden estar influyendo en la toma de una u otra opción. Sin duda este es un tema amplio y suficientemente complejo como para abordarlo a cabalidad en este espacio. Por eso nos concentraremos en describir las relaciones más importantes que pudimos establecer con los datos que teníamos disponibles. La primera relevante señala que el género constituye un factor de peso al momento de explicar la opción por una u otra modalidad. El cruce entre las variables sexo y modalidad muestran que entre las mujeres predomina una clara tendencia a preferir la modalidad HC por sobre la TP. La matrícula femenina en esta modalidad llega al $62 \%$, muy por sobre el $38 \%$ que opta por una formación en el área técnica. Eso a pesar que varios establecimientos de mujeres que hasta hace pocos años impartían solamente la modalidad $\mathrm{HC}$, han venido incorporando el área técnica como parte de su oferta educativa. Entre los hombres, la relación se invierte. De hecho, el $61 \%$ de ellos sigue la modalidad TP, y el 39\% la HC. Estas diferencias de género que se producen en una y otra modalidad son interesantes y de algún modo nos coloca frente a la reproducción vía institución escolar de modelos culturales que definen roles para cada género, y que afloran sobre todo en la construcción de la identidad masculina fuertemente asociado al aprendizaje de oficios técnicos, con el rol de hombre trabajador-sostenedor al centro de la elección. Pero quizás más interesante es notar que los patrones culturales de «división del trabajo» entre géneros se expresan aún más marcados al observar las diferencias entre hombres y mujeres en la modalidad TP misma. De hecho, en establecimientos que imparten oficios industriales, hay una enorme diferencia entre uno y otro sexo ${ }^{10}$ la diferencia se reduce en otras áreas mixtas — diseño gráfico, cocina — y se revierte en el área comercial y otros oficios «femeninos» (vestuario, por ejemplo) que integran la oferta educativa tanto de establecimientos mixtos como de establecimientos femeninos polivalentes. ${ }^{11}$

10 En el Liceo Industrial de Viña del Mar, por ejemplo, de 843 alumnos encuestados, sólo 47 eran mujeres. En los establecimientos mixtos, solamente en el área técnica-comercial la matrícula femenina supera a la masculina.

11 Polivalentes se le llama a los establecimientos que imparten formación en ambas modalidades. 
La segunda relación relevante nos introduce de lleno en el plano de la construcción de las subjetividades, o de los modos de pensar que subyacen a la opción por una u otra modalidad. En el cuestionario incluimos varias preguntas que intentaban registrar las razones en que se fundaron las decisiones. Los resultados muestran que entre quienes optaron por la modalidad TP, el 31\% dice haberlo hecho pensando en sus posibilidades de acceder al mundo del trabajo, proporción considerablemente más alta que el $3 \%$ que dice lo mismo entre quienes optaron por la modalidad HC. Esta relación se invierte cuando se observan las proporciones de cada grupo que optó pensando en sus posibilidades de continuar estudios superiores, que es significativamente más alta entre los $\mathrm{HC}(34 \%)$ que entre los TP $(11 \%)$. Al mismo tiempo, la mayor parte $(66 \%)$ de quienes optaron por la modalidad TP, lo que más valora de la educación es que entrega herramientas para enfrentar el mundo laboral, a diferencia del $7 \%$ de los $\mathrm{HC}$ que dieron la misma respuesta. Para la mayor parte de los $\mathrm{HC}(62 \%)$, lo más valioso de la educación es que entrega una base de conocimientos para continuar estudios superiores, que entre los TP representa solamente al $12 \%$. Por otro lado, independiente de la modalidad elegida, la mayor parte de los jóvenes asume que su decisión es producto de la propia voluntad, una decisión que tomaron solos, cuyo principal motivo fueron los «gustos y las motivaciones personales». Por todo esto, queda claro que estamos ante dos formas diferentes de plantearse la relación entre educación y futuro. Cada una tiene su lógica y su dosis de pragmatismo; pero difieren en su sentido. Una sigue el discurso más típico sobre la educación secundaria, que la pone como preparación para continuar estudios superiores, sobre todo universitarios, y otra que se orienta al mundo del trabajo, heredera del discurso escolar que tenían las Escuelas de Artes y Oficios de otros tiempos.

Queda por ver si existe o no relación entre la modalidad seguida y factores asociados al origen. La respuesta es positiva. En efecto, aunque la mayoría declare que la suya fue una decisión estrictamente personal, hay elementos que permiten suponer que la influencia del grupo familiar es mayor de lo que ellos mismos reconocen. Si hacemos un cruce entre el nivel de escolaridad y la modalidad, resulta que en los grupos de jóvenes con padres que tienen un mayor nivel de escolaridad, tiende a ser más alta la proporción que opta por la formación $\mathrm{HC}$, y más alta la matrícula en la modalidad TP entre quienes tienen padres con niveles bajos de escolaridad. En este sentido, si la decisión por una u otra modalidad contiene una asignación de sentido 
a la relación entre educación y futuro, datos como este nos permiten señalar que la dirección que se le asigne expresa un asunto bastante más complejo que nos lleva al plano de la «construcción social de subjetividades», o de los «modos de pensar» de un grupo, que son el punto donde se cruzan lo estructural, lo intersubjetivo y lo biográfico. A modo de hipótesis, si asumimos que los grupos con menor escolaridad presentan trayectorias históricamente más ligadas al trabajo que a la educación, es posible suponer que desde esa situación se generan con más fuerza lógicas que lleven a preferir — con una mezcla de valoración y pragmatismo - una salida más directa hacia el mundo del trabajo que a la continuación de estudios. Y por el otro lado, si tenemos en cuenta que la opción por la modalidad HC es mayor mientras más años de escolaridad tienen los padres, se puede pensar que en estos grupos se tiende a traspasar con más fuerza que en los de menos escolaridad un discurso que pregona la continuación de estudios. Estas tendencias ciertamente no son absolutas, pero sí son relevantes, y volveremos sobre ellas cuando analicemos la construcción de los «proyectos de vida».

\section{b) Sobre el rendimiento}

En La escuela y la (des)igualdad, Casassus plantea que si hasta no hace mucho las diferencias en los niveles de cobertura mantenían al criterio «años de escolaridad» como el más potente mecanismo de selección social, con los avances en términos de cobertura habría perdido su potencia y cedido su lugar al nivel de rendimiento (Casassus, 2003:26). Aunque estos enunciados tiendan a obviar el peso de otros factores que entran en la selección social - capital social, clase, etc.—, tiene la virtud de concederle cierto margen de posibilidad al «mérito», que no resulta del todo ilusorio si tenemos en cuenta que los mecanismos de selección universitaria le otorgan una ponderación al rendimiento. De ahí la importancia que tiene incluir al análisis de las trayectorias el tema del rendimiento, que será el centro de lo que sigue.

Lo primero en este punto fue observar la distribución de la población en términos de rendimiento. Para medirlo, tomamos como indicador el promedio de calificaciones del último año, en la escala chilena de calificaciones del 1 al 7, que se quiera o no, sigue siendo el indicador más directo disponible. A partir de este dato se definieron cinco rangos de calificaciones, que luego fueron recodificados en un índice

de tres categorías. Lo primero que resalta al revisar las frecuencias es 
la marcada concentración de casos en el tramo de notas intermedio, que va del 5.1 al 6.0. En esta categoría se ubica el 57\% de los casos, lo que a primera vista no sería un mal indicador, teniendo en cuenta que constituye un rango de notas, si se quiere, «aceptable». Por debajo del 5.0 se ubica el $25 \%$ de los casos, y por sobre el 6.0 , el $17 \%$, que corresponde al grupo con más alto rendimiento.

Estas diferencias en el rendimiento pueden ser leídas como grados diferentes de acumulación de capital escolar, que como ya dijéramos, es una de las principales herramientas para producir efectos sobre las trayectorias. La pregunta inevitable es ver, entonces, cuáles son los factores que están influyendo sobre el rendimiento. Según plantea el mismo Casassus, este ejercicio debiera formar parte de los objetivos centrales para cualquier investigación en el campo educacional. En adelante veremos los resultados que pudimos obtener sobre este punto.

i) El factor establecimiento

La motivación principal del trabajo de Casassus fue demostrar que lo que ocurre dentro del espacio escolar resulta fundamental al momento de explicar las desigualdades de rendimiento. Este es el predicamento central de quienes promueven la intervención en la efectividad del proceso educativo como estrategia para mejorar la calidad de la educación. Por nuestra parte, los datos confirman que el rendimiento no es independiente del establecimiento. Esta relación se observa desde varias entradas. Si analizamos los resultados de cada establecimiento en las últimas pruebas SIMCE, resulta que sólo tres de los doce establecimientos superaron los 250 puntos, ${ }^{12}$ dos de ellos son los únicos que en la PSU 2003 obtuvieron un puntaje promedio por sobre los 450 puntos, que es el mínimo exigido para postular a las universidades del Consejo de Rectores, los mismos dos que presentan los menores porcentajes de casos en los niveles más bajos de rendimiento y los porcentajes más altos en el tramo superior de notas. ${ }^{13}$

Ahora bien, el descubrimiento que Casassus reconoce como el más notable de la investigación que le tocara dirigir, fue la influencia que adquirió sobre el nivel de rendimiento el «clima emotivo» que se

12 El Liceo de Niñas de Viña del Mar, el Liceo Comercial de Quillota y el Liceo Guillermo Rivera de Viña del Mar.

13 Estos son el Liceo de Niñas de Viña del Mar y el Liceo Comercial de Quillota. 
produce en un establecimiento. Como escribe el mismo, «el efecto de esta variable, por sí solo, 'pesa' más en los resultados que todos los otros factores reunidos» (Casassus, 2003:157). Por la importancia que reviste, intentamos explorar si había o no relación entre el nivel de rendimiento y la percepción que tienen los propios jóvenes sobre el clima de su liceo. Para eso incluimos una serie de preguntas relativas al clima escolar, y a partir de ellas elaboramos un índice en tres categorías. Lo que obtuvimos fue que efectivamente los mayores niveles de evaluación positiva del clima escolar se registran en el grupo con mejor rendimiento. El punto está en que esta relación la pudimos verificar solamente a nivel individual y no de establecimiento, que es donde Casassus ubica su análisis. Siempre de acuerdo a nuestros datos, al cruzar la evaluación que hacen los jóvenes sobre el clima de su establecimiento con los resultados de las últimas mediciones estandarizadas a nivel nacional, resulta que no necesariamente los establecimientos que han obtenido mejores resultados son los mejor evaluados por sus alumnos. El Liceo Agrícola de Quillota resultó el mejor evaluado, con cerca de un $60 \%$ que describe como positivo su clima interno, a pesar que en términos comparativos es el segundo con peores resultados en las pruebas SIMCE y PSU. Lo contrario ocurre con el Liceo de Niñas de Viña del Mar, que pese a compartir el liderato en términos de resultados con el Liceo Comercial de Quillota, es el segundo peor evaluado.

Con esto no pretendemos negar la importancia que puede tener el clima interno en el proceso de aprendizaje. Por el contrario, de acuerdo a nuestros resultados, si el establecimiento está asociado al rendimiento, en lo que más se nota esa relación es en el clima discursivo que se genera respecto a la educación. Como veremos más adelante, el plano de las disposiciones - discursivas y prácticas - que adoptan los jóvenes frente a la educación y los estudios, son factores que influyen fuertemente sobre el rendimiento, y en esto sí que los procesos que se generan al interior de un establecimiento puede representar un factor relevante. De hecho, si volvemos a los dos establecimientos con mejores resultados, las proporciones de casos que muestran ciertos hábitos de estudio y que adoptan una actitud «resilente» hacia el rendimiento, son considerablemente más altas que en el resto de los establecimientos. A su vez, en estos dos establecimientos se concentra la mayor proporción de casos que aspira a lograr metas más altas de escolaridad y que más quiere continuar estudios de nivel universitario. Sin embargo, la otra «coincidencia» es que estos mismos establecimientos son 
los que cuentan con mayores proporciones de casos con padres que tienen niveles de estudios iguales o superiores a la media completa, y que de todos los establecimientos que participaron del estudio, son los únicos dos que aplican mecanismos para la selección del ingreso. Estos dos últimos datos, a nuestro entender, resultan fundamentales, aunque vuelvan relativo el efecto sobre el rendimiento que pueden estar produciendo factores ligados a la gestión o a la calidad del proceso educativo mismo.

\section{ii) El factor sociocultural}

Varias investigaciones y teorías sostienen que para analizar los factores que determinan las desigualdades en el rendimiento académico, una clave de lectura obligada es partir asumiendo las diferencia en las posiciones de arranque en la «carrera escolar». La idea de fondo es que la antigüedad y la intensidad del contacto que han mantenido las distintas clases o grupos con la cultura que imparte la escuela, determina las condiciones en que cada nuevo individuo inicia su carrera. Los argumentos se basan en principios cognitivos básicos, y en lo medular postulan que en aquellos grupos o familias que históricamente han estado más cercanas a la cultura escolar, que suelen equivaler a «cultura dominante» y a «grupos dominantes», cada nueva generación se «impregna» de ella antes y mejor que las nuevas generaciones de otros grupos que se han mantenido más distantes de esos códigos y símbolos. Así se explica que mientras los primeros están aprehendiendo fácil y rápidamente los contenidos que imparte la escuela, los segundos están empeñados en reducir los déficit heredados $\mathrm{y}$ «nivelar» conocimientos.

De acuerdo a los análisis que pudimos realizar, considerar este piso base resulta importante para entender las variaciones en los niveles de rendimiento. En efecto, la presencia o no de problemas de aprendizaje en el ciclo básico apareció como una de las variables que más se relacionaba con el promedio. Por eso es tan importante lo que ocurra en este ciclo. Lo complejo es que si ya era elevado el $73 \%$ que dijo haber tenido algún tipo de dificultad para aprender en la básica, en la media esa proporción aumenta y llega al $88 \%$. Peor aún, $71 \%$ de quienes no tuvieron problemas en la básica ahora en la media sí los tiene, y sólo un 6\% de quienes tuvieron problemas en la básica logró superarlos. Este dato es relevante, pues estaría reflejando un problema de efectividad en el proceso educativo que se desarrolla en la escuela 
básica, que no lograría construir procesos de aprendizaje efectivos que involucren al conjunto de los alumnos; y eso, en gran medida, remite el asunto a un problema técnico-pedagógico.

Ahora bien, uno de los indicadores socioculturales básicos para medir el contacto de un grupo con la cultura escolar es el nivel de escolaridad de las generaciones adultas. Sobre la importancia de este factor existe suficiente evidencia. Muchos estudios han demostrado que las variaciones en los niveles de escolaridad en buena medida explican las dificultades de aprendizaje y las variaciones en el rendimiento. Por nuestra parte, sólo nos limitaremos a confirmar que la herencia de «capital escolar» efectivamente mantiene un grado de relación con ambas variables. Sin embargo, corresponde señalar también que esas relaciones no aparecen con la intensidad que se hubiera pensado en un primer momento. De hecho, tanto en los porcentajes de casos que tuvieron dificultades en la básica como en los niveles de rendimiento, las variaciones que se producen al pasar de un nivel de escolaridad a otro no resultan muy significativas. Esto no quiere decir que el rendimiento esté completamente separado de lo que ocurra en el grupo familiar. Por el contrario, y esto es lo que queremos destacar, nuestra impresión es que, más que los años de escolaridad de los padres, es el contexto discursivo que se construye al interior del grupo familiar el aspecto más relevante. Lo que se diga en la familia sobre la educación representa una de las principales fuentes desde donde los jóvenes elaboran su relación con los estudios. Varios pasajes de las conversaciones ilustran este punto.

Creo que todo parte de la familia, que te motiven o no. Por lo menos mi papá y mi mamá ninguno tuvieron la posibilidad de estudiar en la universidad. Mi papá ni siquiera terminó la enseñanza media, llegó hasta séptimo básico, pero mi mamá ha hecho dos veces la enseñanza media. Entonces, el ver yo a mi mamá, una señora adulta que ya tiene 45 años, que esté estudiando y ver que se esfuerza por tener notas y sacar cuarto medio, más me motiva (Alumna de Quillota).

En este sentido, la opinión, la valoración, la actitud que tengan los padres o los «adultos significativos» sobre «la Educación» como concepto y como herramienta, son elementos que resultan fundamentales para la construcción del discurso y actitud del sujeto-estudiante. Y en el mismo sentido, también es importante la actitud que asumen los padres frente al proceso educativo de su hijo. Este es un factor del 
rendimiento ya demostrado por varias investigaciones. De ello depende si el ambiente psicosocial que se produce al interior del espacio familiar es favorable o no para el aprendizaje. Así, por ejemplo, al preguntarles a los jóvenes sobre la actitud más frecuente de sus padres cuando obtienen malos resultados, se observa que hay variaciones más o menos importantes en el rendimiento dependiendo del tipo de reacción que adopten. La conclusión más destacable es que en el grupo de más bajo rendimiento se observa una proporción comparativamente más alta de casos que tienen padres cuya reacción más frecuente es punitiva, con un reto o un castigo, y una menor proporción de casos con padres que intentan acompañar el proceso y ayudan a resolver los problemas de rendimiento. Es cierto que estas variables entran en la maraña de elementos que conforman la dinámica de las relaciones intrafamiliares, terreno por cierto ajeno a la escuela. Pero eso no quita explorar espacios e instancias para involucrar a las familias en el proceso educativo y tocar estos y otros temas relevantes. La apertura de estos espacios están, de hecho, contemplados en la ley de la reforma escolar. El problema es que no son muchos los establecimientos que lo han incorporado como una práctica permanente y sistemática.

Hay una última variable sociocultural que mostró grados de relación relevantes con el rendimiento: el lugar o comuna de residencia. La mayoría de los diagnósticos que se le han aplicado al sistema escolar coinciden en señalar que el espacio sociogeográfico en que está emplazado un establecimiento es una variable que guarda relación con la calidad del proceso educativo. Por lo general la conclusión más inmediata es que los establecimientos «rurales» obtienen más bajos resultados que los «urbanos». Cuando aparece uno rural con buenos resultados, se cita como anécdota o como caso especial. Uno de los pocos que relativiza estas conclusiones es nuevamente Casassus. Dice que cuando se aplican procesamientos estadísticos que «ajustan» las variables relativas al contexto familiar, el efecto de la variable sociodemográfica disminuye su peso sobre el rendimiento (Casassus, 2003:146147). Los resultados de nuestro estudio de algún modo comparten estos enunciados, pero van más allá. En efecto, y sorprendentemente, al cruzar el nivel de rendimiento con la comuna donde funciona el establecimiento, resultó que los porcentajes más altos de casos con bajo rendimiento no estuvieron en la comuna más «rural» —en este caso, Puchuncaví - sino en la ciudad más urbanizada - Viña del Mar- En esta inversión del dato seguramente puede estar influyendo el hecho que el estudio de Casassus incluya establecimientos de todo tipo - privados 
y públicos; rurales y urbanos- - Sin embargo, o por lo mismo, vale la pena preguntarse las razones que podrían estar detrás de estas diferencias de rendimiento que observamos entre establecimientos municipalizados y que corren a favor de los establecimientos emplazados en ambientes más rurales o menos urbanizados. ¿Son factores intraescolares los que marcan la diferencia, los procesos pedagógicos, los criterios de evaluación; o los factores más relevantes están fuera de la escuela, en el «contexto»? Lamentablemente sólo contamos con el dato que verifica la tendencia y carecemos de información suficiente para adelantar alguna explicación. Sin embargo, nos parece que junto al estudio de lo intraescolar, se pueden explorar dimensiones de corte cualitativas o antropológicas; buscar, por ejemplo, la influencia que pudiera generar sobre el rendimiento lo que representa la escuela o el liceo en el contexto de cada espacio local, o lo que representa la educación para sus habitantes más jóvenes; todos temas que, por cierto, corresponden a otro tipo de estudios.

iii) El sujeto-individuo

Hasta el momento hemos dado cuenta de los factores del rendimiento que se inscriben en el contexto social y escolar. Pero el análisis sobre el rendimiento no puede cerrarse a la posibilidad de que los sujetos incidan sobre su propio éxito o fracaso escolar. La noción misma de sujeto la deja abierta. ${ }^{14}$ En lo que viene analizamos lo que ocurre al incluir aspectos que entran en este plano.

- El trayecto

En un anterior momento intentamos describir el trayecto que han seguido los jóvenes en su relación autodidacta con la cultura. Los indicadores básicos fueron dos índices. El primero describía el nivel de consumo cultural, y el segundo, el grado de acceso-manejo de herramientas de modernización. En este apartado analizamos brevemente la relación entre estos dos índices y el rendimiento. Creemos que este es

14 La noción de sujeto en el fondo da cuenta del individuo en su cara de sociedad: por un lado, sujeto-sujetado a la estructura y a los discursos sociales (subjetividad); por otro, sujeto-reflexivo capaz de pensar la subjetividad desde su individualidad, y sujeto de acción, capaz de incidir en el curso de sus propios procesos. 
un ejercicio que permite ampliar el radio de análisis del rendimiento escolar, que cuando introduce variables extraescolares, suelen restringirse a variables estructurales, si se quiere, más «duras» — estrato socioeconómico, escolaridad de los padres-, que dejan de lado otras dimensiones extraescolares más abiertas a lo que llamamos la «disposición» del sujeto hacia la adquisición activa de cultura.

Los resultados que produjeron los cruces entre el rendimiento y estos dos índices justificaron su inclusión al modelo. En efecto, el cruce entre el consumo cultural y el nivel de rendimiento muestra que la relación entre ambas variables es positiva y con una intensidad importante. La tendencia es que aquellos con un nivel de consumo cultural alto, tienden a ubicarse en mayor medida en el tramo más alto de calificaciones. Lo mismo ocurre con el grado de manejo de herramientas de modernización, que también mantiene una relación importante y positiva con el rendimiento, en grados aún más fuertes que el consumo cultural.

Con esto se pone en evidencia lo permeables que son los muros de la escuela a las prácticas culturales de los estudiantes. Pues si bien se la puede figurar como un «sistema», como un conjunto de relaciones que se cierra sobre sí mismo, en el mundo social, como alguna vez dijera Habermas, siempre será difícil saber dónde termina un sistema y comienza otro. Lo que borra las fronteras es el carácter cultural de «lo social», su carácter lingüístico, que se cuela o se filtra por todo cierre o clausura física (Habermas, 1990). Por eso son tan importantes este tipo de prácticas, porque si en la escuela se promueve un tipo específico de cultura, que es lo que decía Bourdieu (cf. Bourdieu, 1996), o una lengua, diría un lingüista, toda práctica que contenga algún grado de contacto con esa forma de cultura representa un insumo que incide directa o indirectamente sobre el rendimiento, que no es sino una representación - casi siempre numérica - del grado en que se la ha aprehendido. Es precisamente lo que ocurre con el consumo cultural y las herramientas de modernización. El primero, acerca a las expresiones de la cultura en sus distintos formatos - escrito, audiovisual, etc.- - y teje vínculos con las formas de pensamiento, conocimientos y símbolos que la sostienen. El segundo, conecta a los mundos que se están construyendo, pone «al día» con los nuevos lenguajes. Y en la medida que ambos aportan una integración más amplia a los códigos culturas dominantes, en la medida que entregan herramientas que complejizan los procesos cognitivos y reflexivos, sirven de soportes para el proceso educativo. De ahí que en este punto se reflota el desa- 
fío que en un apartado anterior dejáramos planteado a los establecimientos de educación municipal, en este caso, secundaria, en tanto instancias capaces de generar procesos virtuosos en estos planos.

- El oficio de estudiante

Varios autores han señalado que en su relación con el sistema escolar, los sujetos tienen la capacidad de procesar los códigos que lo regulan y adecuar sus comportamientos a los requerimientos que les impone (cf. Baeza, 2004). A este aprendizaje adaptativo se le ha llamado el «oficio de estudiante». En este punto intentamos abordar algunos aspectos que forman parte de este oficio. Para ello buscamos dos entradas complementarias: una que se ubica en el plano «práctico» de las disposiciones hacia los estudios, y otra que se sitúa en un plano más «discursivo».

Para la primera, utilizamos indicadores bastante simples. De ellos, el que mostró los grados de relación más fuertes con el rendimiento fue la frecuencia con que se aplican técnicas de estudio. Nótese que del total de la muestra, la proporción total de casos que las aplica regularmente es bastante baja: sólo el 12,6\% dice que siempre recurre a una de ellas cuando prepara una prueba o control. No obstante, el efecto que produce es que más de un tercio de este grupo se ubica en el tramo superior de notas, mientras una proporción casi idéntica de quienes nunca las aplican queda en el tramo de rendimiento más bajo. En este sentido, por el grado de relación que adquiere con el rendimiento, representa un aspecto a reforzar, y en eso la escuela juega el rol más importante. Pues como toda técnica, son aprendizajes específicos, que sólo se logran con el ejercicio sistemático y prolongado. Por eso la necesidad de incorporar tiempos escolares destinados exclusivamente a la formación en este tipo de habilidades, de explorar distintas vías o mecanismos para que los estudiantes puedan «aprender a aprender», sobre todo en la educación básica, que es el período en que se pueden desarrollar con más potencia aprendizajes como estos que entran en el terreno de los hábitos.

Ahora bien, es indudable que toda disposición práctica hacia los estudios tiene un fondo discursivo. Lo discursivo tiene que ver con «lo que se dice», pero también representa una fuente para «lo que se hace». De ahí que variables como las aspiraciones que el sujeto construye respecto a su propio rendimiento hayan resultado fundamentales para entender las variaciones en el rendimiento. En efecto, se produce una estrecha relación entre el nivel de resultados que se busca obtener, y el 
grado de autoexigencia que cada uno se impone, con los resultados académicos. La forma de esa relación es circular: quienes aspiran a un mayor rendimiento, tienden a ubicarse en mayor medida que los otros grupos en los rangos superiores de nota; y entre quienes tienen altos niveles de rendimiento, prima una tendencia a querer mantener su posición y seguir entre «los mejores del curso». El punto a destacar es que este conjunto de disposiciones individuales hacia los estudios presenta un grado de relación con el rendimiento que es comparativamente más fuerte que el de los factores relativos al espacio escolar y al contexto sociocultural. Estos últimos pueden tener un peso suficiente cuando se analizan las diferencias de rendimiento entre poblaciones disímiles, como pueden ser, en el caso de Chile y de otros países, las que asisten al sistema público municipal y al particular pagado. Pero la influencia de estos factores «estru-culturales» se suaviza cuando se analizan las diferencias de rendimiento entre estudiantes que asisten a un mismo tipo de establecimiento y proceden de grupos más o menos cercanos u homogéneos. En estos contextos, las disposiciones prácticas y discursivas que elaboran los sujetos frente a la educación y los estudios resultan las más determinantes para despegarse del grueso del grupo y generar trayectorias ascendentes. Quizás por lo mismo en los grupos de discusión fue notoria la presencia de una lógica que concibe el éxito escolar como resultado de la propia acción. Este efecto individualizante que produce la educación parece ser una de sus características más intrínsecas. Por algo el curso escolar se representa como una carrera, que es siempre una competencia. De ahí que la idea que el éxito o el fracaso depende «de uno mismo» $\mathrm{o}$ «del propio interés» haya representado uno de los tópicos más reiterados en las conversaciones. Esto lo confirman el hecho que el $83 \%$ de los jóvenes encuestados asume la falta de estudios y preparación como la principal causa de un mal resultado en una prueba o control, y que cerca del $61 \%$ dice que su preocupación (o despreocupación) por los estudios es un asunto de voluntad personal.

No obstante la presencia de este discurso individualizante $-\mathrm{O}$ «autoflagelante», como se quiera-, no hay duda que la motivación hacia los estudios tiende buena parte de sus raíces en la forma que asume el intercambio en el proceso educativo mismo. Este tiene, según dijera Basil Bernstein, un carácter eminentemente comunicativo, y si no logra construir canales y mecanismos adecuados de comunicación, tiene grandes probabilidades de volverse infructuoso. Está probado que cuando un alumno desatiende es porque no «engancha» con los métodos pedagógicos que se aplican. De ahí que en este punto la 
responsabilidad retorne al establecimiento y a quienes juegan el papel de guías o mediadores en el proceso educativo. A nuestro entender, buena parte de los obstáculos que enfrenta la enseñanza en los establecimientos municipales tiene que ver con lo difícil que ha resultado elaborar nuevos códigos de comunicación entre un cuerpo docente acostumbrado a tener en el aula a una población de estudiantes que pertenecía principalmente a la "clase media», que es a la que ellos mismos pertenecían o pertenecen, y una población escolar compuesta cada vez en mayor proporción por jóvenes que provienen de las clases más populares, que hasta no hace mucho tenían escasa presencia en la secundaria. No deja de ser sintomático que para el $61 \%$ de los profesores, lo que más dificulta su labor docente es el tipo de alumno con el que debe trabajar, muy por sobre otras asociadas a elementos institucionales y de recursos pedagógicos. ${ }^{15}$ De ahí que un primer paso sea cambiar la imagen con que los profesores se representan a sus propios estudiantes, que sin duda constituye una traba para el intercambio intraescolar. Para los jóvenes, este tema resulta fundamental. De hecho, una y otra vez las conversaciones volvían al problema de la relación alumno-profesor, que reconocían trabada por varios flancos, muchos de ellos ligados a los «pequeños detalles» que forman parte de las relaciones cotidianas. La sensación que queda es que las demandas más profundamente compartidas por los jóvenes no fueron tanto por el lado de la efectividad, sino por el de la afectividad. En varios pasajes de las conversaciones asomaron palabras y frases que reflejaban la presencia de relaciones basadas en la imposición, el temor, la lejanía o la parcialidad, de algún modo símbolos de la «antigua pedagogía». Quizás por eso cerca de un 70\% mal evaluó el clima de su liceo, y cuando les preguntamos sobre el grado de apoyo que sienten por parte de sus profesores, el 63\% dijo que era insuficiente. De ahí, en parte, se pueden entender algunos brotes de conflictividad al interior del liceo, o expresiones como «la fuga», que más representan lo que ocurre en un recinto penitenciario que en un establecimiento educacional.

\section{PROYECTOS Y ASPIRACIONES}

Los puntos anteriores nos han permitido recorrer algunos aspectos que forman parte del trayecto que han seguido estos jóvenes hasta tiempo

15 Los antecedentes corresponden al resultado de una encuesta que fue aplicada al cuerpo docente y que formaba parte de este mismo estudio. 
presente. Ahora intentaremos establecer un puente entre lo que ha sido este trayecto y lo que los jóvenes anticipan como cursos de trayectorias posibles para sus vidas futuras. Creemos que la presencia del futuro en esta etapa de la vida es inevitable. Quizás esto se deba a que la finalidad de la educación secundaria es, por definición, la de preparar a las generaciones jóvenes para su ingreso a la educación superior y/o al mundo del trabajo. Se puede decir que a quienes estén cursando la secundaria, «la sociedad» les concede un tiempo para que resuelvan el dilema de decidir qué quieren hacer a futuro. Este es uno de los aspectos que más se repite cuando se intenta definir a «la juventud» como etapa de la vida y como «categoría social». De ahí la frecuencia con que se asocia el concepto de juventud a la idea de «latencia» o de «preparación». Por eso en este punto intentamos describir las principales tendencias sobre lo que los jóvenes de estos establecimientos municipalizados aspiran alcanzar en términos de escolaridad y lo que piensan hacer al momento de egresar de la secundaria. Posteriormente, intentamos buscar algunos factores que pudieran estar marcando diferencias en uno y otro aspecto.

\section{Sobre el carácter de los proyectos}

Al explorar las principales tendencias en la configuración de las proyecciones hacia el futuro, aparecen varios datos relevantes. El primero es que hay una proporción importante de casos que quiere dejar como tope máximo de escolaridad la secundaria, que hoy en día se ha instalado como el nivel mínimo exigido tanto por la ley como por el «mercado laboral». Esta es, de hecho, la segunda alternativa en importancia - llega al 22\% - , que en líneas generales tiende a ser preferida más por los hombres que por las mujeres, por quienes asisten a la modalidad TP que a la HC, y por quienes pertenecen a familias con menores niveles de escolaridad. Lo segundo es que también es relevante la proporción de casos que todavía no tiene claro qué piensa hacer a futuro, más aún si consideramos que es una situación que no mantiene mayor relación ni con la edad ni con el nivel escolar. Pero sin duda que lo más importante es que una amplia mayoría de casos está pensando en continuar estudios de nivel superior, y más aún, que ellos corresponden a estudios, por sobre todo, de nivel universitario. A pesar que el porcentaje que se siente preparado para ingresar a la universidad sólo llega al 6\% del total de casos, ésta aparece como la máxima aspiración para el $47 \%$, muy por sobre las alternativas que representan 
los Institutos Profesionales (15\%) y los Centros de Formación Técnica $(5 \%)$. En cierta medida, esta tendencia puede ser esperable. De lo que estamos hablando es de respuestas que tienen mucho de sueños, de anhelos; por eso se entiende la fuerte adhesión que genera la universidad, que es la instancia que mejor simboliza el ideal del «desarrollo integral» y la promesa del «ascenso social» por la vía de los estudios. Pero lo más interesante de este dato es que contrasta ampliamente con la imagen que tienen los profesores de sus propios alumnos, que tienden a verlos como sujetos sin mayores aspiraciones o apáticos respecto a su propio futuro.

Eso en el plano de las aspiraciones o de los anhelos declarados. Ahora bien, tan importante como representar los sueños que se formulan, es explorar lo que cada uno piensa hacer al momento de egresar de la secundaria. Nos parece que una pregunta de este tipo, a diferencia de la anterior, obliga a situarse frente al futuro como algo inevitable y a pensar en alguna alternativa concreta de salida o en un camino a seguir. Como era de esperar, los datos en este punto se correlacionan fuertemente con los del anterior. Aunque desciende a un $16 \%$, se verifica que hay un porcentaje relativamente importante de casos que quiere ingresar inmediatamente al mundo del trabajo, que en líneas generales responde al mismo perfil de quienes querían solamente completar la educación secundaria. También se mantiene en el mismo nivel la proporción de casos que no sabe lo que quiere hacer al terminar este ciclo escolar. Y, por último, también aquí los proyectos más frecuentes tienen que ver con continuar estudios superiores.

La información extra que entrega esta pregunta es que entre quienes aspiran continuar estudios superiores, se configuran distintas lógicas o estrategias para alcanzarlos. Entre ellas, la más frecuente, que representa al 35\% de los casos, tiene que ver con seguir estudios superiores inmediatamente después de concluida la secundaria, que es la postura que más fielmente representa el curso de vida que propone el discurso escolar en su acepción más «pura», que promueve la linealidad sin inter-fases entre los estudios secundarios y superiores. La segunda alternativa en importancia, que agrupa al $24 \%$, aplica la misma lógica de continuidad lineal de los estudios, pero con la variante de combinar estudios y trabajo. La sola introducción del factor de actividad laboral genera una diferencia que resulta fundamental, no sólo porque puede estar reflejando lógicas proyectivas diferentes que pueden depender de la capacidad de las familias para absorber el costo que significa la educación superior - que en términos estrictos consi- 
dera el arancel y otros gastos anexos, pero que en términos menos estrictos también incluye, por ponerlo en el lenguaje de la economía, los «costos marginales» que conlleva la inactividad de uno de sus miembros jóvenes - , sino porque al volverse laboralmente activo, el sujeto produce una forma particular de ser joven, una particular condición juvenil, la de estudiante-trabajador, más cargada de responsabilidades que la de quienes solamente estudian, con otros tiempos y otra relación con los estudios.

Esta necesidad de distribuir un mismo tiempo entre trabajo y estudio desaparece con la tercera alternativa en importancia, que agrupa a quienes piensan trabajar un tiempo y después estudiar. Aquí la estrategia es diferente. No combina las condiciones de estudiante y trabajador; las alterna: posterga la de estudiante y asume la de trabajador, para luego volver a la de estudiante. Este tipo de fenómenos están a la base del concepto de trayectoria yo-yo que hace un buen tiempo viene planteando Machado Pais cuando intenta dar cuenta de estos formatos de juventud que van y vuelven de una condición a otra. Lo interesante es notar que en este grupo se encuentra la mayor proporción de casos que piensa que los factores más importantes para seguir estudios superiores son los económicos. Seguramente por eso tratan de buscar un piso financiero que les permita abrir la posibilidad de un posterior ingreso a la educación superior, y quizás por eso también son el grupo que más pensaría en el costo y la duración de la carrera al momento de elegir una. Ahora, si bien es cierto que la alternativa de trabajar primero y estudiar después resultó la que genera menos adhesión, no por eso se convierte en la menos probable. De hecho, y esta es la cualidad que comparten todas estas proyecciones, si por un lado bosquejan algunas imágenes sobre un futuro personal y anticipan algunas estrategias, ellas son inciertas por definición, imposibles de anticipar por completo. Nada asegura que estas aspiraciones se cumplan, que las metas se logren y que se haga del modo en que se quiere. Esto corre para todos, pero sobre todo para los jóvenes que pertenecen a los sectores con menos «capitales», que en el plano de los estudios - y en otros también- no cuentan con las mismas seguridades que los jóvenes de otros sectores o clases.

\section{Algunos factores de los proyectos}

Tratar de buscar algunas variables que estén influyendo sobre las proyecciones que elaboran estos jóvenes, nos coloca ante un desafío teó- 
rico y práctico complejo. Primero porque nos pone al centro del problema sobre los motivos de la «acción social», que sigue, y seguramente, seguirá siendo un dilema teórico de difícil solución. Segundo, porque nos obliga a realizar una serie de procedimientos para obtener resultados fiables y llegar a observaciones fundadas. En fenómenos complejos como éstos siempre queda la posibilidad de dejar fuera algunas variables; pero ese es un riesgo que hay que asumir. Para reducir ese riesgo, realizamos una primera selección ampliada de variables que guardaran relación con las metas escolares y los proyectos de vida, y tras una serie de evaluaciones, se decantaron las más importantes. Los resultados nos permitieron distinguir tres tipos de variables relevantes: uno que tiene que ver con lo que ya hemos llamado el trayecto de los sujetos; otro que se relaciona con el curso escolar; y un tercero asociado a las disposiciones hacia el discurso escolar.

En el primer factor, las relaciones más fuertes tienen que ver nuevamente con el grado de herramientas de modernización y de consumo cultural. La tendencia es que mientras mayor sea el nivel en estos índices, más altas son las metas escolares propuestas y más se adhiere al camino de los estudios. Aunque comparativamente es más significativo el efecto del índice de herramientas de modernización que el del consumo cultural, estos datos confirman la importancia que adquieren estas dos facetas para la configuración de las trayectorias. $\mathrm{Su}$ efecto ha demostrado ser transversal; toca al rendimiento, pero también entra en el complejo de elementos que ayudan a definir «objetivos» en la vida o asignarle un sentido al futuro.

Cuadro 2

Aspiraciones de escolaridad por nivel de rendimiento

\begin{tabular}{|l|c|c|c|c|}
\hline Aspiraciones & Bajo & Medio & Alto & Total \\
\hline No lo tiene claro & $18,9 \%$ & $12,3 \%$ & $8 \%$ & $12 \%$ \\
\hline Terminar la secundaria & $37,2 \%$ & $23,2 \%$ & $7,5 \%$ & $21,5 \%$ \\
\hline Ingresar a un CFT & $7,3 \%$ & $5,5 \%$ & $2,5 \%$ & $5,1 \%$ \\
\hline Ingresar a un IP & $12,3 \%$ & $16,3 \%$ & $8,5 \%$ & $14,7 \%$ \\
\hline Ingresar a la universidad & $24,3 \%$ & $42,6 \%$ & $73,5 \%$ & $46,7 \%$ \\
\hline
\end{tabular}

El segundo tipo de variables nos introduce en el trayecto propiamente escolar. Aquí las relaciones más expresivas fueron el nivel de rendimiento y el grado de preparación que cada uno siente tener para en- 
frentar con éxito los estudios universitarios. Ambas variables están relacionadas entre ellas. Para ilustrar el sentido de la relación, nos remitiremos a los efectos que produce el rendimiento.

$\mathrm{Al}$ observar el Cuadro 2, se advierte que el único grupo en que la alternativa de completar la secundaria representa la aspiración más frecuente, es el de rendimiento más bajo. Ya al pasar al grupo con un nivel intermedio de rendimiento, que como viéramos es el que concentra a la mayoría de los casos, la alternativa de ingresar a la universidad pasa a ser la más frecuente, aunque la alternativa de solamente terminar la secundaria sigue en el segundo lugar. Es interesante notar, además, que en este grupo se da la mayor frecuencia de casos que espera ingresar a un Instituto Profesional, que representa una alternativa de formación técnica superior a medio camino entre la capacitación y la formación universitaria. Como era de esperar, en el grupo con mayor rendimiento hay una clara tendencia a concentrar las aspiraciones en el ingreso al sistema universitario, muy por sobre las otras alternativas, y también en este grupo se observa la menor proporción de casos que todavía no define bien lo que quiere, que crece en la medida que disminuye el rendimiento.

El efecto del grado de preparación para los estudios universitarios sigue el mismo sentido, aunque su relación con las aspiraciones escolares es aún más intensa. Lo importante es señalar el efecto que producen estas variables. En la medida que ambas informan al sujeto sobre las posibilidades que le asigna el sistema escolar, regulan las apuestas que se lanzan y marcan los caminos que aparecen como más factibles de seguir. En este sentido, no resulta extraño que si el rendimiento influye en el nivel de escolaridad que espera alcanzar y en el grado de adhesión hacia el camino de los estudios, también ayuda a disipar la indecisión o la indefinición de cara al futuro. De hecho, si en términos generales el porcentaje de casos que no tiene claro qué quiere hacer y cómo hacerlo es alto, es significativamente mayor en los grupos con menor rendimiento. De ahí que si el futuro es incierto por definición, la acumulación individual de mayores niveles de capital escolar, ayuda a reducir esa incertidumbre.

El tercer tipo de variables explora distintos aspectos vinculados a la adscripción manifiesta respecto a la alternativa de los estudios como herramienta y camino para elaborar un «proyecto de vida». Aquí se incluyeron una serie de preguntas que trataban de definir el «sentido» que se le atribuye a la permanencia en la educación secundaria y de medir la importancia que se le otorga a la continuación de estudios 
postsecundarios. Los resultados que obtuvimos demostraron que estas variables no eran marginales. Por el contrario, fueron precisamente éstas las que mostraron los niveles más fuertes de relación con las metas educacionales. Esto es sin duda relevante, pues retorna a su centro el carácter eminentemente discursivo que encierra el camino de la educación. En efecto, el discurso que se elabore sobre la educación, o sobre la relación entre estudios y futuro, influye fuertemente en las aspiraciones que se depositan en el camino de los estudios. La atribución de valor es fundamental, y hay una estrecha relación entre lo que se valora de la permanencia en la institución escolar y el tipo de meta educacional a la que se aspira. La tendencia es que quienes ven la educación secundaria como un puente hacia los estudios de nivel superior, son los que en mayor medida se proponen metas escolares más altas, representadas en este caso por la figura de «la universidad», mientras quienes la ven como un proceso que entrega herramientas para ingresar al mundo del trabajo, tienden a orientar sus aspiraciones más hacia este campo. En este punto es donde adquiere toda su importancia la modalidad de formación elegida. De hecho, como vimos en un apartado anterior, hay una fuerte relación entre el aspecto que se valora de la educación y la modalidad, ${ }^{16}$ que al mismo tiempo es una de las variable que más pesa al momento de configurar las metas escolares. También es importante el grado de importancia que se le asigna a la continuación de estudios superiores. Las más altas apuestas de escolaridad y la mayor adhesión a la educación superior se asocian a los grupos que colocan a la no continuación de estudios superiores como el mayor temor de sus vidas presentes, por sobre otras más ligadas al plano de la construcción de familia, el logro de un bienestar económico o de estabilidad laboral. Por otro lado, la formulación de metas escolares más altas se asocia fuertemente a la presencia de un discurso que liga la continuación de estudios con la realización personal, componente básico del discurso escolar. Cuando preguntamos por los criterios que aducirían al momento de decidirse por una carrera de educación superior, el ideal del desarrollo de las habilidades y los gustos personales fue la lógica más frecuente entre todas las alternati-

16 Las tendencias indicaban que quienes optan por la modalidad TP valoran en mucho mayor medida que los que optan por la $\mathrm{HC}$ la «formación para el trabajo» que entrega el liceo, mientras estos últimos tienen una presencia ampliamente mayoritaria entre quienes privilegian la adquisición de conocimientos para continuar estudios. 
vas; sin embargo, se producen variaciones considerables dependiendo del nivel de estudios al que se aspira. En el grupo que quiere solamente completar la educación media, los porcentajes que adhirieron a esta lógica fueron los más bajos, crecieron en la medida que las metas escolares iban subiendo, y llegaron a su más alta frecuencia en el grupo que anhela ingresar a la universidad, que al mismo tiempo fue el con más baja adhesión a lógicas de decisión más pragmáticas como el costo o la duración de una carrera, que son comparativamente más importantes entre quienes aspiran ingresar a un Centro de Formación Técnica y a un Instituto Profesional.

Lo otro importante es que estas lógicas que se aplican a la elección de una alternativa académica, también se expresan al momento de configurar una imagen ideal de trabajo. El discurso que propone una continuidad lineal entre trabajos y estudios es fuerte, pero lo es más entre quienes aspiran lograr altas metas educacionales. La idea de trabajar en algo relacionado con los estudios cursados y en un trabajo donde se puedan realizar los intereses personales es la lógica más extendida, y su presencia es mayor mientras más alto es el nivel de escolaridad al que se aspira. Por su parte, en los grupos que se proponen bajos niveles de escolaridad, nuevamente asoman lógicas con mayores dosis de pragmatismo, que se expresan en que en estos grupos son más altos los porcentajes que cuando imaginan un trabajo, privilegiarían el que mejor les pague o que aceptarían cualquier tipo de trabajo.

Con todo, lo relevante es destacar el lugar que adquiere el plano discursivo cuando los jóvenes dotan de contenido sus imágenes de futuro. Se puede decir que la adhesión al discurso escolar tiene un componente importante de creencia. No por nada en el epílogo de su Historia de la enseñanza en Chile, Amanda Labarca, se declaraba una «apóstol» de la Educación (cf. Labarca, 1939). Quizás por eso mismo es que estas imágenes las elaboran por sobre las constricciones que suponen las condiciones de origen, o de clase. Si utilizamos como referente la escolaridad de los padres, podemos ver que si bien mantiene un grado de relación con el tipo de meta escolar, la intensidad de esa relación es poco significativa. Tampoco resulta decisivo el hecho que la gran mayoría de los jóvenes que participó del estudio sienta que tiene pocas posibilidades de alcanzar sus metas en el marco que impone la distribución social de oportunidades en Chile. Ni una ni otra alcanzan para regular completamente las expectativas de los sujetos, que se supone era una de las funciones fundamentales del sistema escolar (cf. Bourdieu, 2003). Su única faceta que todavía la cumple es 
la diferencia entre modalidades de educación, pero su alcance es parcial. Al parecer, la potencia que viene adquiriendo el discurso escolar como discurso social dominante para la construcción de futuro es lo que mejor explica este fenómeno.

No podemos cerrar este apartado sin incluir una última variable: el género. Sin duda es un dato notable que tanto las proporciones que aspiran a seguir estudios superiores como las que aspiran completar estudios universitarios sean considerablemente mayores entre las mujeres que entre los hombres. Mientras de los hombres el 26\% aspira ingresar a la universidad, entre las mujeres ese anhelo representa al $55 \%$; es decir, cerca de un $20 \%$ más que entre los hombres. Esta es una tendencia que se ha venido registrando en otras mediciones. Como señala el informe del PNUD, la concentración de las apuestas femeninas en la alternativa educacional se produce porque ella ha demostrado ser la principal herramienta para la integración efectiva de las mujeres al mundo del trabajo (PNUD, 1998). Lo interesante es que en este caso se trata de mujeres jóvenes que pertenecen a los estratos de menos recursos, lo que desde ya encierra un cambio en la «mentalidad femenina» de la mayor importancia. De hecho, en los grupos de discusión la idea de no ser lo que fueron o no vivir lo que vivieron las madres, fue un tópico recurrente en la conversación de las mujeres. No hay que perder de vista que estamos tratando con un sector de la población en que la mujer ha tendido a concentrar sus actividades en ocupaciones mal posicionadas y mal remuneradas, o en labores ligadas directamente al hogar. Por eso la nueva «imagen ideal» de mujer tiende a despegarse de la mujer dedicada a las labores del hogar y acercarse más a la de mujer independiente, profesional y que participa del mundo laboral, identidades femeninas históricamente más ligadas a la situación de las mujeres en las clases medias y altas que a las de sectores obreros y populares.

\section{PROYECTOS DE VIDA Y CONDICIÓN JUVENIL}

Históricamente la condición de joven ha estado ligada a la de estudiante. De ahí que la palabra juventud haya tenido como referente principal a las generaciones jóvenes de las clases alta primero y media también después, que eran las que mayoritariamente participaban de la secundaria y casi exclusivamente de la superior. La extensión de la

cobertura y las mayores tasas de permanencia en la educación secundaria por parte de la población joven de los sectores obreros- 
asalariados en un principio, y «marginales» después, significó la conformación de nuevas condiciones juveniles, diferentes a las que habían producido otros sectores de la sociedad. Este fenómeno constituye una de las transformaciones culturales más potentes que trajo la expansión del sistema escolar. La sola permanencia en la secundaria hasta los 18 o incluso hasta los 20 ó 21 años, que para anteriores generaciones de estas clases eran edades en que muchos ya trabajaban y/o habían formado familia, implica ya un cambio generacional importante. La posibilidad de contar con un pequeño lapso para proyectarse hacia el futuro pasó a ser también una experiencia para las generaciones jóvenes de estos grupos y eso, inevitablemente, va configurando nuevos modos de plantear la relación con el tiempo y los ciclos vitales, elemento que ha sido y sigue siendo angular para toda forma de cultura.

Uno de los aspectos que más notoriamente expresa el carácter que adquieren estas transformaciones en la subjetividad juvenil de estos sectores, es el modo en que están planificando sus vidas. Quizás el hecho mismo que la estén planificando es ya un dato relevante. Hay varias entradas que pueden servir para dar cuenta de las tendencias que asumen estos planes. Una de las más ilustrativas la encontramos en la planificación de la conformación de familia. En un dato que es coincidente con los de varias otras mediciones (cf. INJUV, 2002; 2004), se observa una tendencia a posponer la edad para tener hijos. Poco más del 77\% planea tener su primer hijo después de los 24 años; $55 \%$ entre los 25 y los 29 años, y 22\% lo quiere dejar para después de pasar a su tercera década de vida. Resulta interesante notar además el alto porcentaje de casos missing en esta pregunta $(13,5 \%)$, indicador que hay un grupo no menor de jóvenes que simplemente está desechando la alternativa de tener hijos o no es un tema a plantearse en estos momentos. Ahora, el problema está en que del $31 \%$ que se declara sexualmente activo, poco más de la mitad usa algún método anticonceptivo, lo que tarde o temprano se puede traducir en que muchos de los sexualmente ya iniciados y de los que en adelante se inicien, se vean forzados a asumir la maternidad o la paternidad, y a replantear el modo en que venían pensando su futuro.

En cuanto a los modelos de familia, predomina una imagen que se ajusta al modelo nuclear. De hecho, cerca del $44 \%$ piensa formar una familia con hijos. No obstante, hay una proporción relativamente importante de casos que está optando por otros modos de vida, con una pareja, pero sin tener hijos, o por una vida declaradamente individual, viviendo solos o solas. Este dato es interesante, porque aquí no 
estamos hablando de situaciones «de la vida real» que de hecho se presentan, como la madre-soltería o la pareja sin hijos, sino de predisposiciones a querer o anhelar estas situaciones para la propia vida.

Al igual que el nacimiento del primer hijo, también hay una tendencia a posponer el matrimonio. Cuando les preguntamos por la edad aproximada a la que querían casarse, algo más del $80 \%$ dijo que después de los 24 años. De ellos, casi un $50 \%$ dijo que entre los 25 y los 29 años, y $31 \%$, que después de los treinta. La fuerte correspondencia que se observa entre la edad a la que se quiere tener el primer hijo y la edad para casarse, indica que la conformación de familia y el matrimonio todavía van de la mano y que aún predomina la secuencia matrimonio-hijos, que es el curso de vida que impone la norma cultural. De todos modos, hay proporciones de casos que no se ajustan a la norma, que no supeditan el nacimiento de un hijo al matrimonio, o que no asocian el matrimonio a la reproducción; y otra proporción importante que simplemente desecha la alternativa de casarse, visible en el alto valor que alcanzan los casos missing — llegan al 24\%-, entre ellos muchos que dijeron querer casarse a los 99 años o edades similares, en una ironía que refleja su falta de identidad con el matrimonio.

No deja de ser llamativo el efecto que produce el tiempo que se asigna a cada uno de estos hitos sobre el tipo de familia que se quiere construir o el modo de vida que se piensa llevar. En los grupos que quieren tener a más temprana edad un hijo, más se adhiere a la imagen de familia nuclear unida formalmente por el matrimonio. Por el contrario, en los grupos que quieren postergar el nacimiento del primer hijo, más se adhiere a la idea de vivir solos, o con una pareja, pero sin hijos. Lo otro que llama la atención es la diferencia de género que se produce en los modos de plantearse estos aspectos del futuro. La imagen de familia nuclear con hijos está bastante más presente entre los hombres que entre las mujeres, que a su vez piensan o quieren en mayor medida que los hombres vivir solas. Paralelamente, entre los hombres hay una tendencia más fuerte que entre las mujeres a querer ser padres a edades más tempranas — antes de los 25 años-, aunque también es mayor entre los hombres el porcentaje que lo pospondría para después de cumplida la treintena. El matiz de diferencia, que se repite en el caso del matrimonio, es que las mujeres tienden a planificar su maternidad principalmente para edades que están entre los 25 a los 29 años, probablemente por razones vinculadas a la fertilidad o a los relatos sobre los problemas de alumbramiento pasados los treinta. 
Aunque es menos notoria que en el caso de la maternidad/paternidad y el matrimonio, también se observa una tendencia a posponer el tiempo para independizarse del hogar materno, lo mismo que la edad para convertirse en laboralmente activo. ${ }^{17}$ Estos dos hitos se encuentran estrechamente ligados. La edad para «emigrar» o «dejar el nido» guarda, de hecho, una fuerte correspondencia con la edad en que se quiere ingresar al mundo del trabajo. Uno y otro hito también mantienen un grado de relación con la edad para el matrimonio y la conformación de familia, pero no lo demasiado estrecha como para sostener que la búsqueda de independencia y de trabajo se asocia siempre a la conformación de familia propia. Más estrecha es la relación que mantienen con la edad a la que se espera concluir los estudios, lo que plantea que estos tres hitos, estos tres pasos, van unidos y que son los que la mayor parte de estos y estas jóvenes primero piensa realizar. En este sentido, se puede decir que en el modo en que se planea el futuro se mezclan todos estos elementos, forman una amalgama, una masa que se alarga o acorta, que se alisa o enreda dependiendo del tiempo que se asigne para cada etapa o para cada uno de estos hitos que van marcando la conversión de un niño en adulto, lo que en otro momento hemos llamado la «estructura de las transiciones» (cf. Dávila, Ghiardo y Medrano, 2005). Lo importante es que al fondo de estas variaciones se encuentran los distintos modos en que se plantea la relación entre estudios, trabajo e independencia. En líneas generales, quienes quieren terminar cuarto medio y no piensan continuar estudios superiores, son los que piensan ingresar más tempranamente al mundo del trabajo, que también expresan su intención de independizarse del hogar a más temprana edad, sea para conformar familia o simplemente para vivir solos. Por su parte, quienes quieren alcanzar mayores niveles de escolaridad, que por lo general son más entre quienes siguen actualmente la modalidad $\mathrm{HC}$ que la TP, y entre las mujeres que entre los hombres, tienden a prolongar en mayor medida que los otros grupos la edad a la que esperan lograr la independencia de su hogar, trabajar, tener un hijo y casarse. Así es como cristaliza el

17 En rigor casi el 50\% señaló haber trabajado en algún momento de sus vidas. De ellos, hay un porcentaje relativamente menor que se mantiene activo, trabajando todos los días o sólo los fines de semana. La situación mayoritaria, sin embargo, es mantener sólo una condición de estudiante, y en el caso de trabajar, hacerlo principalmente en temporada de vacaciones o sólo esporádicamente. 
efecto cultural que produce la adscripción al discurso escolar, que dependiendo de su extensión, o de su nivel, genera modos diferentes de plantear la extensión y hasta el orden de los hitos que le dan forma a los ciclos vitales.

Sin embargo, más allá de sus variaciones, hay un elemento que subyace a todas estas lógicas de construcción de futuro y es el predominio de una postura por sobre todo «pragmática». Cuando preguntamos por los requisitos más importantes para formar una familia propia, la alternativa más importante fue lograr antes una buena situación económica, que concentró al $45 \%$ de los casos, y la segunda, con el $30 \%$, tenía que ver con el haber completado los estudios. Es decir, entre estas dos alternativas, que correlacionan fuertemente, se llevan el $75 \%$ de los casos. Independiente del nivel de escolaridad al que se aspira, de la modalidad, del género o del grupo de origen, la búsqueda de un bienestar económico mediado por los estudios, resume la demanda de estos jóvenes, lo que desde ya plantea un desafío social y político complejo: la necesidad de garantizar a cada alternativa de formación - tanto a la Humanista Científica como a la Técnica Profesional - y a cada opción de educación superior - a la universitaria, a la profesional y a la técnica-, un grado de seguridad que resulta impensable de continuar las tendencias que ha seguido la estructura ocupacional de la última década, que ha tendido a privilegiar los títulos universitarios, sobre todo los del área administrativa, y a estancar a los oficios técnicos intermedios (cf. León y Martínez, 2001).

\section{PARA Terminar}

En lo que fue este texto pudimos recorrer algunos aspectos relevantes que forman parte de los trayectos que han seguido los jóvenes que asisten al sistema municipalizado, y pudimos explorar las principales tendencias sobre los distintos modos en que están proyectando sus vidas. ${ }^{18}$ Cierto es que lo que hemos podido registrar son sólo anticipaciones llenas de imaginación, futuros posibles, anhelos de una situación futura. No podemos saber lo que ocurra en adelante, si en el futuro efectivamente se haga lo que se aspira, que se llegue a ser lo que

18 Creemos que el hecho que el estudio se concentre en una región específica del país, en este caso la V Región de Valparaíso, las principales tendencias pueden extenderse sin problemas a lo que ocurre en otras zonas del país. 
hoy día se quiere. Como dice la canción, los caminos de la vida no siempre son los que se esperan. Pero es precisamente por revelar la carga de esas aspitaciones, por representar los anhelos de estos jóvenes, que estudios de este tipo se vuelven relevantes. Más cuando se trata de jóvenes que pertenecen a los sectores de la población con menos posibilidades. No importa que el futuro sea algo inconcluso, imposible de anticipar desde ahora; lo importante es que hemos podido explorar algunos componentes de esos anhelos, que son reflejo, en el fondo, de los anhelos que están presentes en las «subjetividades sociales».

Ahora, si lo ponemos en clave de trayectorias sociales, lo más importante es que si bien los datos muestran que el capital escolar heredado por el grueso de los alumnos del sistema municipalizado es bajo, los niveles de escolaridad de las distintas fracciones vienen en aumento. A ritmos diferentes, pero todos en aumento. Que una cuarta parte de los padres haya completado la secundaria, refleja ya un giro respecto al nivel de escolaridad de sus antecesores, los adultos mayores, cuyos niveles de escolaridad son más bajos que el resto de la población, sobre todo en los estratos más bajos (cf. Mideplan, 2001). Los efectos de este fenómeno a nivel de la subjetividad de los grupos es notorio. De hecho, cuando la madre o el padre completa la educación secundaria, se genera una inflexión respecto a los grupos de menor escolaridad al cruzar esta variable con cualquiera que indague el curso escolar o las aspiraciones y proyectos futuros. Además, el hecho mismo que estos jóvenes se encuentren actualmente de camino a completar la educación media, para muchas familias primera generación que alcanzaría ese nivel, cambia las formas de generación de juventud y modifica las estrategias de reproducción legítimas en los sectores populares, tradicionalmente más ligadas al trabajo que a la escolarización. La presencia de estas lógicas a nivel de la mentalidad de estos grupos, o del habitus, como diría Bourdieu, es evidente y quedó grabada en varios pasajes de las conversaciones grupales. A pesar que el discurso se haya producido desde la vivencia de la desventaja respecto a los jóvenes de otras clases, que se expresa en la sensación de inferioridad del estudiante del sistema público municipalizado frente al de los sistemas subvencionados y particular pagado, el discurso que pregona a la educación como única vía que asegura trayectorias ascendentes forma parte central del habla respecto al futuro. En efecto, los proyectos más frecuentes que los jóvenes piensan realizar al terminar la secundaria se ligan principalmente a la continuación de estudios, aunque para lo- 
grarlo deban combinar trabajo y estudios o trabajar primero para luego estudiar; y de las alternativas que ofrece el sistema de educación superior, el ingreso a la universidad es la aspiración mayoritaria.

En este sentido, el efecto de trayectoria que arrastra el cambio en las estrategias que formulan quienes hoy son jóvenes, que cristaliza en la legitimidad y valoración que atribuyen al camino escolar, contiene también una cara generacional. En el habla de estos sujetos, los padres ya no representan la imagen a imitar, sino el límite a superar. No quieren ser lo que es el padre o la madre, sino más que ellos. La idea de surgir es un punto fundamental y marca el tono de su discurso. Todos quieren surgir y el camino que aparece más efectivo es el de la escolarización. El futuro no deja de ser incierto, puede estar en sus ciudades o en otro lugar, incluso en otro país, pero no hay dudas que cualquiera sea el camino que se tome, «los estudios» son indispensables, un requisito para «ser alguien en la vida», pero también para «ser mejores personas», en una frase repetida que refleja que sobre la educación todavía quedan depósitos sobre su potencia para generar un «progreso moral», que era parte central del ideario educativo de la modernidad.

La pregunta que queda es hasta qué punto la sociedad o el «sistema social» en su conjunto está preparado para responder a la demanda por educación que se plantean. Y luego, hasta qué punto será capaz el sistema productivo de integrar a cada nueva oleada de egresados. Pregunta pertinente, teniendo en cuenta que la proliferación de instituciones de educación superior en todos sus tipos y en todas las regiones del país, ha multiplicado varias veces la cantidad de títulos que se oferta, mientras el sistema productivo no se expande a la misma velocidad, sobre todo en el sector de las ocupaciones técnicas intermedias, que es precisamente donde se ha tendido a concentrar el nivel de estudios de quienes han egresado del sistema municipalizado. Pregunta pertinente también si tenemos en cuenta que en la sociedad chilena no basta con el rendimiento ni con el nivel de estudios para ascender en la «escala social». Como lo han demostrado estudios recientes, al momento de la selección laboral, más importantes que el título obtenido resultan la cantidad y el nivel de contactos - el capital social-, el apellido y el nombre del colegio de procedencia, lo que los investigadores llaman el background, o lo que viene a ser lo mismo, la condición de clase (Núñez y Martínez, 2004).

Si el tiempo limita el análisis de las trayectorias y lo deja inconcluso, se requiere entonces abordar iniciativas de investigación que 
permitan darle continuidad, seguir la trayectoria que sigan los sujetos en períodos posteriores, descubrir si lo que hoy día piensan se corresponde luego con lo que fue de sus vidas, y sobre todo, con lo que en ese momento piensen.

VALPARAÍSO (CHILE), NOVIEMBRE 2005

RECIBIDO: NOVIEMBRE 2005

ACEPTADO: DICIEMBRE 2005

\section{REFERENCIAS BIBLIOGRÁFICAS}

BAEZA, JORGE (2004): El oficio de estudiante. Santiago: UCRSH.

Bourdieu, Pierre (1988): La distinción. Criterios y bases sociales del gusto. Madrid: Taurus.

— y JeAn-Claude Passeron (2003): Los herederos. Los estudiantes y la cultura. Buenos Aires: Siglo XXI.

- $\mathrm{y}-$ (1996): La reproducción. Elementos para una teoría del sistema de enseñanza. México: Fontamara.

CASASSUS, JUAN (200: La escuela y la (des)igualdad. Santiago: Lom.

CIDE (2003): «IV encuesta a actores del sistema educativo». Santiago: CIDE.

DÁvila, Oscar; Felipe Ghiardo y Carlos Medrano (2005): Los desheredados. Trayectorias de vida y nuevas condiciones juveniles. Valparaíso: Ediciones CIDPA.

HABERMAS, JÜRGUEN (1990): La lógica de las ciencias sociales. Madrid: Tecnos.

Instituto Nacional de Estadísticas De Chile (INE) (2005): Encuesta sobre consumo cultural y uso del tiempo libre. Santiago: INE.

Instituto NACIONAL DE LA JuventUd De ChILE (INJUV) (2004): Cuarta encuesta nacional de juventud 2003. La integración social de los jóvenes en Chile 1994-2003. Santiago: INJUV.

LabarCa, Amanda (1939): Historia de la enseñanza en Chile. Santiago: Publicaciones de la Universidad de Chile.

LEÓN, ARTURO Y MARTÍNEZ, JAVIER (2001): «La estratificación social chilena hacia fines del siglo XX». Serie de Politicas Sociales No 52 . Santiago: CEPAL.

MACHADO PAIS, JosÉ (2000): «Las transiciones y culturas de la juventud: formas y escenificaciones». Revista Internacional de Ciencias Sociales $\mathrm{N}^{\circ} 164$. París: Unesco.

MidePLAN (2003): «Encuesta Casen 2003. Principales resultados en educación». Santiago: Mideplan. 
(2001): «Situación de la educación en Chile, año 2000. Análisis de la VIII Encuesta de Caracterización Socioeconómica Nacional (Casen 2000)». Documento No4. Santiago: Mideplan.

PNUD (1998): Desarrollo humano en Chile: las paradojas de la modernización. Santiago: PNUD.

NÚÑEZ, IVÁN y ROBERTO MARTíNEZ (2004): «Classism, discrimination and meritocracy in the labor market: the case of Chile». Documento de Trabajo N 208. Santiago: Departamento de Economía, Universidad de Chile.

UnIVERSIDAD DE ChILE (2004): Compendio estadístico. Proceso de admisión año académico 2004. Santiago: DEMRE, Universidad de Chile. 